\title{
Assessing rates of parasite coinfection and spatiotemporal strain variation via metabarcoding: insights for the conservation of European Turtle Doves Streptopelia turtur
}

\author{
Rebecca Thomas ${ }^{1}$, Jenny Dunn ${ }^{2}$, Deborah Dawson ${ }^{3}$, Helen Hipperson ${ }^{3}$, Gavin Horsburgh ${ }^{3}$, \\ Antony Morris ${ }^{4}$, Chris Orsman ${ }^{4}$, John Mallord ${ }^{4}$, Philip Grice ${ }^{5}$, Keith C. Hamer ${ }^{1}$, Cyril \\ Eraud $^{6}$, Lormee Herve ${ }^{6}$, and Simon Goodman ${ }^{1}$ \\ ${ }^{1}$ University of Leeds \\ ${ }^{2}$ University of Lincoln \\ ${ }^{3}$ University of Sheffield \\ ${ }^{4}$ Royal Society for the Protection of Birds \\ ${ }^{5}$ Natural England Peterborough \\ ${ }^{6}$ Office National de la Chasse et de la Faune Sauvage
}

January 5, 2022

\begin{abstract}
Understanding the frequency, spatiotemporal dynamics and impacts of parasite coinfections is fundamental to developing control measures and predicting disease impacts. The European turtle dove (Streptopelia turtur) is one of Europe's most threatened bird species. High prevalence of infection by the protozoan parasite Trichomonas gallinae has previously been identified, but the role of this and other coinfecting parasites in turtle dove declines remains unclear. Using a high-throughput sequencing approach, we identified seven strains of T. gallinae, including two novel strains, from ITS1/5.8S/ITS2 ribosomal sequences in turtle doves on breeding and wintering grounds, with further intra-strain variation and four novel sub-types revealed by the iron-hydrogenase gene. High spatiotemporal turnover was observed in T. gallinae strain composition, and infection was prevalent in all populations (89-100\%). Coinfection by multiple Trichomonas strains was rarer than expected (1\% observed compared to $38.6 \%$ expected), suggesting either within-host competition, or high mortality of coinfected individuals. In contrast, coinfection by multiple haemosporidians was common (43\%), as was coinfection by haemosporidians and T. gallinae (90\%), with positive associations between strains of $\mathrm{T}$. gallinae and Leucocytozoon suggesting a mechanism such as parasite-induced immune modulation. We found no evidence for negative associations between coinfections and host body condition. We suggest that longitudinal studies involving the recapture and investigation of infection status of individuals over their lifespan are crucial to understand the epidemiology of coinfections in natural populations.
\end{abstract}

\section{Hosted file}

Rebecca coinfection ms R2_to submit.docx available at https://authorea.com/users/454022/ articles/551771-assessing-rates-of-parasite-coinfection-and-spatiotemporal-strainvariation-via-metabarcoding-insights-for-the-conservation-of-european-turtle-dovesstreptopelia-turtur 